Fetal Diagnosis aur Therapy
Received: March 3,2016

Accepted after revision: September 16, 2016

Published online: October 15, 2016

\title{
Impact of Fetal Weight Estimation on the Prediction of Neonatal Morbidity and Mortality at the Limit of Viability
}

\author{
Jarmila A. Zdanowicz ${ }^{\mathrm{a}}$ Chantal Huber ${ }^{\mathrm{a}}$ Roland Gerull ${ }^{\mathrm{b}}$ Martin Mueller ${ }^{\mathrm{a}, \mathrm{c}}$ \\ Luigi Raio $^{\mathrm{a}}$ Daniel Surbek ${ }^{\mathrm{a}}$ \\ ${ }^{a}$ Department of Obstetrics and Gynecology, and b ${ }^{b}$ Division of Neonatology, Department of Pediatrics, \\ Bern University Hospital, University of Bern, Bern, Switzerland; 'Department of Obstetrics, Gynecology, and \\ Reproductive Sciences, Yale University School of Medicine, New Haven, CT, USA
}

\section{Keywords \\ Estimated fetal weight · Limit of viability · Neonatal outcome $\cdot$ Preterm delivery $\cdot$ Ultrasound}

\begin{abstract}
Introduction: To determine the accuracy of estimated fetal weight (EFW) at the limit of viability in a delivery room setting and its impact on the prediction of neonatal outcome. Material and Methods: In this retrospective, single-center cohort study we included patients with preterm birth between $23 \%$ and $26 \%$ weeks of gestation. Neonates were divided into 3 groups according to birth weight at delivery (accuracy index 90-110\%, <90\%, >110\%). Neonatal outcome for each group was categorized into survival with and without impairment and death, with a follow-up period of 6 weeks. Results: Eighty-seven newborns were included, with $62.1 \%$ accurately estimated. Gestational age at birth, fetal sex, maternal body mass index, and time interval between birth and ultrasound affected the accuracy of EFW. Chances of survival were significantly higher in the underestimated group for birth weight at delivery compared with estimated weight $(p<0.001)$, with risk of death being significantly lower $(p<0.001)$. The reverse was true for overestimated infants,
\end{abstract}

for both risk of death and chances of survival. At 6 weeks' follow-up, there were significantly more deceased overestimated infants $(p=0.041)$. Discussion: Our study shows that inaccuracy of EFW at the limit of viability occurs frequently in a delivery room setting with a potential impact on neonatal outcome.

(c) 2016 S. Karger AG, Basel

\section{Introduction}

Preterm birth, particularly at the limit of viability between $23 \%$ and $26 \%$ weeks of gestation, is associated with high neonatal morbidity and mortality [1]. Physicians and parents are confronted with clinically and ethically difficult decisions, and prediction of adverse outcomes influences this decision process $[1,2]$. In Switzerland, current guidelines recommend primarily palliative care at a gestational age of $22 \%{ }_{7}-23^{6} / 7$ weeks, conditional intensive care at a gestational age of $24 \% /_{7}-24 \% / 7$ weeks depending on additional parameters such as estimated fetal weight (EFW) or antenatal glucocorticoids, and full intensive care after $25 \%$ weeks' gestation $[2,3]$. Notably, the MOSAIC study showed that within Europe, treat-

\section{KARGER}

E-Mail karger@karger.com

www.karger.com/fdt
(C) 2016 S. Karger AG, Basel

$1015-3837 / 15 / 0000-0000 \$ 39.50 / 0$
Prof. Daniel Surbek, MD

Department of Obstetrics and Gynecology

University Hospital Bern, Effingerstrasse 102

CH-3010 Bern (Switzerland)

E-Mail daniel.surbek@insel.ch 
ment for infants born at the limit of viability varies, especially at 24-25 weeks of gestation, showing that Poland, Germany, and Portugal favor an active management already at a GA below 23 weeks [4]. On the other hand, aggressive intervention starting at a GA of $23 \%$ weeks is recommended in the USA [5]. Comparing perinatal care in industrialized countries showed that at 23 and 24 weeks of gestation, active management is not the rule and that overall, at the limit of viability, each case has to be evaluated individually regarding further management [6].

Predicting individual neonatal outcome remains challenging and has been assessed using different models, with gestational age, fetal sex, use of antenatal corticosteroids, single or multiple pregnancy, and estimated fetal birth weight being the most accurate factors [7]. Given the complexity of this approach, the National Institute of Child Health and Human Development (NICHD) Neonatal Research Network developed an online tool to predict neonatal outcome based on a mathematical model in order to facilitate the decision process [8].

Prediction of neonatal outcome depends in part on correctly estimated fetal weight, which may be affected by suboptimal conditions during emergency situations in the delivery room setting. The accuracy of EFW at the limit of viability is susceptible to a variety of confounding factors [9]. We performed a retrospective analysis to determine the accuracy of EFW in the delivery room setting, and how inaccuracy may adversely affect neonatal morbidity and mortality by influencing clinical decisions.

\section{Material and Methods}

\section{Study Design and Data Collection}

We performed a retrospective analysis of our tertiary care University center patient population. At our center, we accommodate 1,700 deliveries each year, including 35\% premature births, and have a neonatal intensive care unit with 34 beds. The study was approved by the institutional review board. We obtained ultrasound data (from delivery room setting), and birth and neonatology reports from charts and electronic databases (Department of Obstetrics and Gynecology and Division of Neonatology). We included only patients who delivered between $23^{\circ} /{ }_{7}$ and $26^{\circ} /{ }_{7}$ weeks of gestation, which is currently the limit of viability in industrialized countries, between 2005 and 2011.

\section{Inclusion and Exclusion Criteria}

Inclusion criteria were gestational age between $23 \%$ and $26 \%$ weeks at delivery, a maximum interval of 7 days between fetal weight estimation in a delivery bed and delivery, complete ultrasound parameters (biparietal diameter, head circumference, abdomen circumference, and femur length), and live-born or intrapartum deceased infants without chromosomal or structural anomalies. For all patients, gestational age was based on the last menstrual period, confirmed with first-trimester ultrasound and adjusted according to crown-rump length if the discrepancy was equal to or greater than 5 days. Singleton, twin, and triplet pregnancies were included. We excluded cases with intrauterine fetal death between $23 \%$ and $26 \%$ weeks of gestation as well as incomplete documentation.

Ultrasound was performed with a GE Voluson E with a transabdominal curved-array transducer probe with a frequency of 7 $\mathrm{MHz}$. Depending on the clinical situation, ultrasound was repeated if women did not deliver within $24 \mathrm{~h}$ after the initial examination.

The following parameters were extracted from available data: singleton or multiple pregnancy, maternal body mass index, gestational age, fetal gender, EFW - calculated in all cases using the Hadlock I formula as determined by biparietal diameter, head circumference, abdomen circumference, and femur length [10] -, amniotic fluid index, presentation of the fetus, location of the placenta, interval between fetal weight estimation and delivery, use of antenatal corticosteroids, presence of ruptured membranes and/or contractions, mode of delivery, birth weight accuracy index (defined as estimated birth weight/birth weight at delivery), whether postnatal intensive care was necessary, and neonatal outcome up to 6 weeks postnatally. In our department, these parameters are routinely assessed in the diagnostic workup before and after delivery. Primary outcome was EFW accuracy in our study group. Secondary outcome was neonatal outcome and specifically, impact on neonatal mortality.

We divided all infants into 3 groups according to the birth weight accuracy index: accuracy index 90-110\% (accurately estimated group), accuracy index $<90 \%$ (underestimated group) and accuracy index $>110 \%$ (overestimated group). Mean percentage deviation and standard deviation were calculated for each group (primary outcome).

Neonatal outcome was categorized into 3 groups: survival without impairment, survival with impairment, and death, for a follow-up period of 6 weeks. Impairment was defined as the presence of one or more of the following diagnoses: bronchopulmonary dysplasia with a need for additional oxygen for more than 28 days postnatally (as defined by Bancalari et al. [11]), necrotizing enterocolitis, and intracerebral hemorrhage grade 3 or higher. Infants without impairment were defined as survival without diagnoses that lead to permanent damage with a negative impact on the infant's quality of life in general and in particular absence of the above-mentioned diagnoses. The decision to administer postnatal intensive care was made based upon individual characteristics in each case.

The risk for overall death and chances of survival were calculated for each infant individually, using a web calculator introduced by Tyson et al. [7] with the NICHD Neonatal Research Network [8]. Calculations were made using both the estimated birth weight and the birth weight at delivery. The mean percentage deviation and standard deviation in the results for risk of overall death and chances of survival for mechanically ventilated infants were then calculated for each group.

\section{Analysis with Adjusted Weight Gain for EFW}

According to a recently published study, the average weight gain for preterm infants at the limit of viability is approximately $15 \mathrm{~g}$ per day [12]. Therefore, we did an additional analysis of our data by adding $15 \mathrm{~g}$ per day between ultrasound and birth to the EFW for each infant. 
Fig. 1. Included and excluded cases. We included 87 of 147 cases that met our inclusion criteria. IUFD, intrauterine fetal death; GA, gestational age.

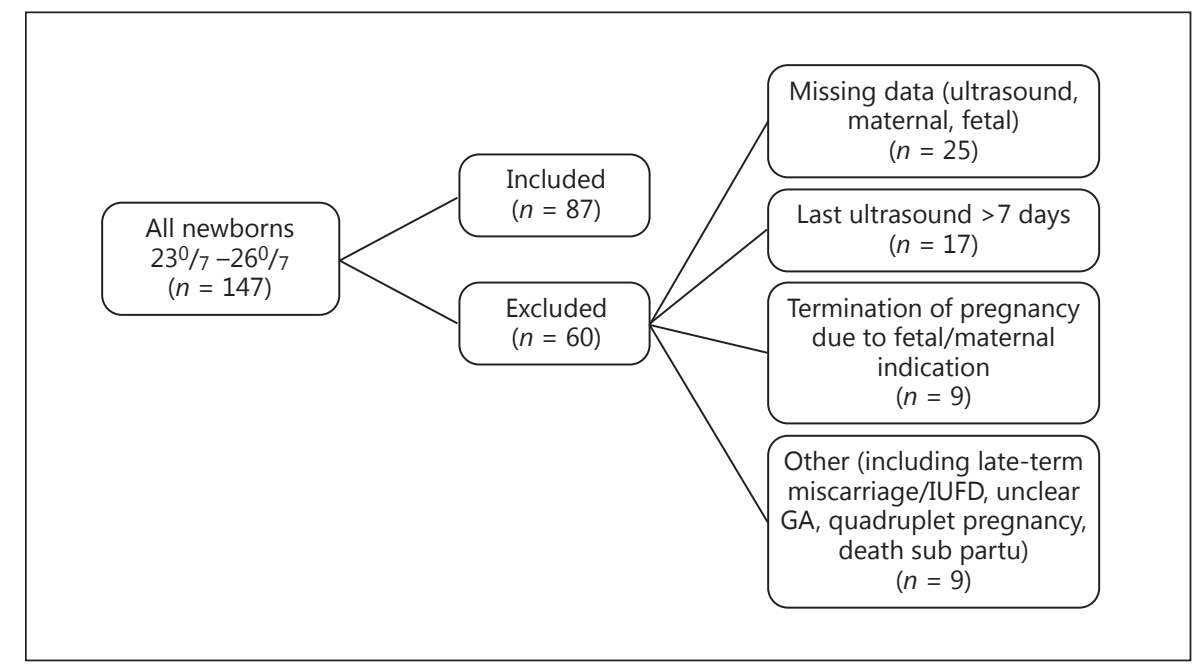

Statistical Analysis

Statistical data analysis was performed using Microsoft Office Excel 2007 and the Statistical Package for the Social Sciences (SPSS) version 21 (2012; SPSS, Inc., Chicago, IL, USA). Mean values and standard deviations were calculated for all factors. Univariate analysis was applied to determine the relationship between EFW and the individual factors possibly affecting EFW (demographic data). $t$ tests were used to compare continuous data and $\chi^{2}$ tests to compare dichotomous data. $p$ values of $\leq 0.05$ were regarded as significant.

\section{Results}

\section{Demographic Data}

From a total of 147 cases, 87 met the inclusion criteria and were used for further analysis (Fig. 1). Demographic data obtained for all included infants are summarized in Table 1 . We detected significant differences regarding gestational age at birth, fetal sex, maternal body mass index, and time interval between birth and ultrasound between the 3 groups: infants in the underestimated group were younger than accurately estimated and overestimated infants with a mean gestational age of $23{ }^{2} / 7$ weeks of gestation and more often male (85.7\%). In the overestimated group, the time interval between ultrasound and birth was shorter with a mean of 1.7 days and the maternal body mass index was higher with 27.1.

\section{Primary Outcome}

As shown in Table 2, EFW was accurate in only 54 (62.1\%) fetuses (mean EFW/birth weight $100.8 \% \pm$ standard deviation 5.5\%). In 14 (16.1\%) fetuses, EFW was un- derestimated (mean EFW/birth weight $84.8 \pm 6.3 \%$ ) and in $19(21.8 \%)$ overestimated (mean EFW/birth weight $118.3 \pm 8.3 \%)$.

\section{Impact on Neonatal Mortality}

To further determine the impact of EFW in our cohort, we used the NICHD Neonatal Research Network online tool, which estimates the risk for overall death and chances of survival based on birth weight. We used both the estimated birth weight and the birth weight at delivery. Given the limitation of the NICHD calculator (birth weight range between 401 and 1,000 g), we used the lowest range limit in 2 infants where birth weight was slightly below $401 \mathrm{~g}$ and the highest range limit in 1 case with a birth weight just above 1,000 g. In addition, we excluded 6 infants as the NICHD calculator accepts a gestational age from 22 to 25 weeks only, and 5 infants due to incomplete data regarding the use of antenatal corticosteroids. Together, a total of 76 infants or 59 infants (mechanically ventilated) were subjected to further analysis. Table 3 summarizes the chances of survival for mechanically ventilated infants $(n=59)$ and the risk of death for all infants $(n=76)$ for the accurate, overestimated, and underestimated group, calculated with the estimated birth weight and the birth weight at delivery, respectively.

We detected several differences. Chances of survival were significantly higher in accurately estimated infants versus overestimated infants $(p=0.012)$ for birth weight at delivery. Risk of death for both estimated weight and birth weight at delivery was significantly lower in accurately estimated versus underestimated infants $(p<$ 
Table 1. Characteristics of all three groups (total $n=87$ )

\begin{tabular}{|c|c|c|c|}
\hline Characteristic & Accurate & $\begin{array}{l}\text { Underesti- } \\
\text { mated }\end{array}$ & $\begin{array}{l}\text { Overesti- } \\
\text { mated }\end{array}$ \\
\hline Number & 54 & 14 & 19 \\
\hline Gestational age at birth, days ${ }^{\mathrm{a}}$ & $24^{6} / 7 \pm 6$ & $23^{2} / 7 \pm 6$ & $25^{0} /{ }_{7} \pm 5$ \\
\hline Minimum & $23^{1} / 7$ & $23^{2} / 7$ & $23 \frac{4}{7}$ \\
\hline Maximum & $26 \%$ & $26 \%$ & $26^{0} / 7$ \\
\hline$p$ value & & $0.030^{\mathrm{b}}$ & $0.591^{\mathrm{b}}$ \\
\hline Mode of delivery: C-section & $34(62.9 \%)$ & $8(57.1 \%)$ & $14(73.7 \%)$ \\
\hline Female & $23(42.6 \%)$ & $2(14.3 \%)$ & $11(57.9 \%)$ \\
\hline$p$ value & & $0.050^{\mathrm{c}}$ & $0.250^{c}$ \\
\hline Fetal lung maturation started & 45 & 8 & 18 \\
\hline Fetal lung maturation complete ${ }^{\mathrm{d}}$ & $34(63.0 \%)$ & $6(42.9 \%)$ & $9(47.4 \%)$ \\
\hline$p$ value & & $0.173^{c}$ & $0.210^{c}$ \\
\hline Multiple pregnancy & $19(35.2 \%)$ & $6(42.8 \%)$ & $5(26.3 \%)$ \\
\hline Twin & $17(31.5 \%)$ & $5(35.7 \%)$ & $5(26.3 \%)$ \\
\hline Triplet & $2(3.7 \%)$ & $1(7.1 \%)$ & $0(0.0 \%)$ \\
\hline$p$ value (singleton/twin/triplet) & & $0.793^{c}$ & $0.609^{c}$ \\
\hline$p$ value (singleton/multiple) & & $0.596^{\mathrm{c}}$ & $0.479^{c}$ \\
\hline Cephalic presentation of fetus & $30(55.6 \%)$ & $5(35.7 \%)$ & $13(68.4 \%)$ \\
\hline$p$ value & & $0.144^{\mathrm{c}}$ & $0.413^{c}$ \\
\hline Anterior location of placenta & $27(50 \%)$ & $5(35.7 \%)$ & $10(52.6 \%)$ \\
\hline$p$ value & & $0.340^{\mathrm{c}}$ & $0.844^{\mathrm{c}}$ \\
\hline \multicolumn{4}{|l|}{ Amniotic fluid index } \\
\hline Normohydramnios & $38(70.4 \%)$ & $9(64.3 \%)$ & $13(68.4 \%)$ \\
\hline Oligohydramnios & $14(25.9 \%)$ & $5(35.7 \%)$ & $3(15.8 \%)$ \\
\hline Polyhydramnios & $1(1.9 \%)$ & $0(0.0 \%)$ & $3(15.8 \%)$ \\
\hline$p$ value & & $0.709^{c}$ & $0.062^{\mathrm{c}}$ \\
\hline Rupture of membranes & $14(25.9 \%)$ & $5(35.7 \%)$ & $4(21.1 \%)$ \\
\hline$p$ value & & $0.492^{\mathrm{c}}$ & $0.643^{c}$ \\
\hline Active labor & $28(51.9 \%)$ & $6(42.9 \%)$ & $9(47.4 \%)$ \\
\hline$p$ value & & $0.507^{\mathrm{c}}$ & $0.683^{c}$ \\
\hline $\begin{array}{l}\text { Time interval between ultrasound } \\
\text { and birth, days }{ }^{\mathrm{a}}\end{array}$ & $2.6 \pm 2.05$ & $2.7 \pm 2.61$ & $1.7 \pm 1.19$ \\
\hline Minimum & 0 & 0 & 0 \\
\hline Maximum & 7 & 7 & 4 \\
\hline$p$ value & & $0.808^{\mathrm{b}}$ & $0.041^{\mathrm{b}}$ \\
\hline Expert sonographer ${ }^{\mathrm{e}}$ & $29(53.7 \%)$ & $9(64.3 \%)$ & $9(47.4 \%)$ \\
\hline$p$ value & & $0.438^{\mathrm{c}}$ & $0.933^{\mathrm{c}}$ \\
\hline Maternal body mass index ${ }^{a}$ & $23.1 \pm 3.49$ & $22.8 \pm 4.69$ & $27.1 \pm 5.30$ \\
\hline$p$ value & & $0.873^{\mathrm{b}}$ & $0.002^{\mathrm{b}}$ \\
\hline
\end{tabular}

Bold font highlights total for given characteristic. ${ }^{a}$ Mean \pm standard deviation. ${ }^{\mathrm{b}} t$ test over-/underestimation versus accurate. ${ }^{c} \chi^{2}$ over-/underestimation versus accurate. ${ }^{\mathrm{d}}$ Completion of full $48 \mathrm{~h}$ of steroids. ${ }^{\mathrm{e}}$ Defined as highly skilled sonographer with proven qualification.

0.001 and $p=0.016$, respectively). Finally, chances of survival were significantly higher in the underestimated group for birth weight at delivery compared with the estimated weight $(p<0.001)$, with risk of death being significantly lower $(p<0.001)$. The reverse was true for overestimated infants, for both risk of death and chances of survival.
Table 2. Primary outcome: definition of groups according to the birth weight accuracy index (total $n=87$ )

\begin{tabular}{llll}
\hline Fetal weight & Accurate & $\begin{array}{l}\text { Under- } \\
\text { estimated }\end{array}$ & $\begin{array}{l}\text { Over- } \\
\text { estimated }\end{array}$ \\
\hline Number & $54(62.1 \%)$ & $14(16.1 \%)$ & $19(21.8 \%)$ \\
Mean EFW, g & 672.5 & 587.9 & 685.1 \\
Mean birth weight, g & 669.6 & 693.7 & 579.5 \\
Mean EFW/birth weight, \%a & $100.8 \pm 5.5$ & $84.8 \pm 6.3$ & $118.3 \pm 8.3$ \\
\hline
\end{tabular}

EFW, estimated fetal weight. ${ }^{a}$ Mean \pm standard deviation.

\section{Secondary Outcome}

Neonatal Outcome for All Infants

The results for neonatal outcome are summarized in Table 4. Of 87 infants, 10 (11.5\%) survived without impairment, 40 (46.0\%) with impairment and 37 (42.5\%) died. For infants who survived without impairment, EFW was accurate in $7 / 10(70.0 \%)$, underestimated in $1 / 10$ (10.0\%), and overestimated in $2 / 10$ infants $(20.0 \%)$. For infants who survived with impairment, EFW was accurate in $27 / 40(67.5 \%)$, underestimated in $5 / 40(12.5 \%)$, and overestimated in $8 / 40$ infants $(20.0 \%)$. For infants who died, EFW was accurate in 20/37 (54.1\%), underestimated in $8 / 37$ (21.6\%), and overestimated in $9 / 37$ (24.3\%) infants.

\section{Neonatal Outcome for Infants Receiving Intensive Care}

Given that neonatal intensive care is essential for neonatal survival, in our cohort, all infants who received palliative care were removed from analysis of factors that may affect the neonatal outcome (Table 5). Infants were subjected to intensive care if EFW was accurate in $42 / 54$ (77.8\%) cases, underestimated in 8/14 (57.1\%) cases, and overestimated in 18/19 (94.7\%) cases. We detected significantly more deceased infants at the 6-week follow-up postnatally in the overestimated versus accurate group (44.4 vs. $19.0 \%, p=0.041$ ).

Neonatal Outcome between $23 \%$ and $24 \% / 7$ Weeks of Gestation

Because at a gestational age between $23 \%$ and $24 \%$ weeks, intensive care is not unconditionally recommended according to Swiss guidelines [2], we further analyzed neonatal outcome for this specific age group.

Overall, 44 infants were between $23^{\circ} / 7$ and $24^{6} / 7$ weeks of gestation. Out of 26 infants in the accurately estimated group, $15(57.7 \%)$ infants died, while most infants died in 
Table 3. Comparison of mean percentages for chances of survival and risk of death calculated with estimated weight and birth weight at delivery for each group using the NICHD online calculator

\begin{tabular}{|c|c|c|c|c|c|}
\hline Possible outcome & Accurate & Underestimated & $p$ value ${ }^{c}$ & Overestimated & $p$ value $^{c}$ \\
\hline Survival $^{\mathrm{a}}$ & $n=37$ & $n=6$ & & $n=16$ & \\
\hline Estimated birth weight, \% & 66.7 & 54.2 & 0.080 & 64.6 & 0.662 \\
\hline Birth weight at delivery, \% & 66.7 & 63.7 & 0.679 & 54.1 & 0.012 \\
\hline$p$ value & 0.903 & 0.000 & & 0.000 & \\
\hline Risk of death ${ }^{b}$ & $n=47$ & $n=12$ & & $n=17$ & \\
\hline Estimated birth weight, \% & 41.7 & 68.8 & 0.000 & 40.9 & 0.891 \\
\hline Birth weight at delivery, $\%$ & 42.0 & 60.1 & 0.016 & 52.2 & 0.117 \\
\hline$p$ value & 0.621 & 0.000 & & 0.000 & \\
\hline
\end{tabular}

Bold font highlights possible outcome. ${ }^{\mathrm{a}}$ For mechanically ventilated infants $(n=59) .{ }^{\mathrm{b}}$ For all infants $(n=76)$. ${ }^{\mathrm{c}} t$ test over-/underestimation versus accurate.

Table 4. Neonatal survival with and without impairment and neonatal death 6 weeks postnatally for each study group

\begin{tabular}{|c|c|c|c|c|}
\hline Neonatal outcome & Total & Accurate & Underestimated & Overestimated \\
\hline Number & 87 & 54 & 14 & 19 \\
\hline Survival & $50(57.5 \%)$ & $34(63.0 \%)$ & $6(42.9 \%)$ & $10(52.6 \%)$ \\
\hline Without impairment & $10(11.5 \%)$ & $7 / 10(70.0 \%)$ & $1 / 10(10.0 \%)$ & $2 / 10(20.0 \%)$ \\
\hline With impairment ${ }^{\mathrm{a}}$ & $40(46.0 \%)$ & $27 / 40(67.5 \%)$ & $5 / 40(12.5 \%)$ & $8 / 40(20.0 \%)$ \\
\hline Death & $37(42.5 \%)$ & $20 / 37(54.1 \%)$ & $8 / 37(21.6 \%)$ & $9 / 37(24.3 \%)$ \\
\hline
\end{tabular}

Bold font highlights neonatal outcome. ${ }^{\text {a }}$ Defined as the presence of one or more of the following diagnoses: bronchopulmonary dysplasia, necrotizing enterocolitis, and intracerebral hemorrhage.

the underestimated group (70\%). When intensive care is administered, more overestimated than accurately estimated infants die; however, this difference is not significant. In addition, intensive care was only applied in $4 / 10$ cases in the underestimated group, but in almost all cases $(7 / 8)$ in the overestimated group and in more than half of the cases in the accurately estimated group (15/26). However, when intensive care was applied in the underestimated group, 3 out of 4 infants survived.

\section{Adjusted Weight Gain for EFW}

Comparing these results to our initial analysis, the distribution of our groups changes to the extent that there are more overestimated infants $(n=39$ vs. $n=19)$, fewer accurately estimated infants ( $n=38$ vs. $n=54$ ), and fewer underestimated infants $(n=10$ vs. $n=14)$. Mean gestational age at birth for overestimated and accurately estimated infants remains the same, while for underestimated infants, the mean gestational age is now $243 / 7$ weeks (vs. $23^{2} / 7$ weeks). More overestimated (70.3\%) and less accurately estimated (52.8\%) infants received fetal lung maturation. There are fewer female infants in the accurately (34.2\%) and underestimated (10.0\%) group, as well as fewer multiple pregnancies $(20.0 \%)$, but more preterm premature membranes $(50.0 \%)$ in the underestimated group. The time interval between ultrasound and birth increases in the overestimated group $(2.8 \pm 1.8$ vs. $1.7 \pm$ 1.2 days) and decreases in the underestimated group (1.3 \pm 1.3 vs. $2.7 \pm 2.6$ days). The mean EFW/birth weight is $102.3 \pm 5.1 \%$ for accurately estimated infants, $85.9 \pm 4.9 \%$ for underestimated infants, and $119.2 \pm 7.7 \%$ for overestimated infants.

However, when comparing the mean percentages for chances of survival and risk of death as calculated using the NICHD online calculator, the only difference to our initial analysis (Table 3) was in risk of death. Now, risk of death for birth weight at delivery was no longer significantly lower in accurately estimated versus underestimat- 
Table 5. Neonatal survival with and without impairment and neonatal death 6 weeks postnatally for all infants to whom intensive care was administered

\begin{tabular}{lllll}
\hline Neonatal outcome & Total & Accurate & Underestimated & Overestimated \\
\hline Number & $68(78.2 \%)$ & $42(77.8 \%)$ & $8(57.1 \%)$ & $18(94.7 \%)$ \\
Survival & $\mathbf{5 0 ( 7 3 . 5 \% )}$ & $\mathbf{3 4}(\mathbf{8 0 . 9 \% )}$ & $\mathbf{6}(\mathbf{7 5 . 0} \%)$ & $\mathbf{1 0}(\mathbf{5 5 . 6 \% )}$ \\
$\quad$ Without impairment & $10(14.7 \%)$ & $7(16.7 \%)$ & $1(12.5 \%)$ & $2(11.1 \%)$ \\
$\quad$ With impairment & & $27(64.3 \%)$ & $5(62.5 \%)$ & $8(44.4 \%)$ \\
$\quad$ BD & $40(58.8 \%)$ & 19 & 3 & 8 \\
$\quad$ NEC & 3 & 1 & 2 \\
$\quad$ ICH & 4 & 0 & 1 \\
Death & $\mathbf{1 8 ( 2 6 . 5 \% )}$ & $\mathbf{8 ( 1 9 . 0 \% )}$ & $\mathbf{2 ( 2 5 . 0 \% )}$ & $\mathbf{8}(\mathbf{4 4 . 4 \% )})$ \\
$p$ value & & $0.700^{\mathrm{b}}$ & $0.041^{\mathrm{b}}$ \\
\hline
\end{tabular}

Bold font highlights neonatal outcome. ${ }^{a}$ Defined as the presence of one or more of the following diagnoses: bronchopulmonary dysplasia (BD), necrotizing enterocolitis (NEC), and intracerebral hemorrhage (ICH) grade 3 or higher. ${ }^{b} \chi^{2}$ over-/underestimation versus accurate.

ed infants; however, it was still considerably lower $(p=$ $0.073)$.

At 6 weeks of follow-up, compared to our initial analysis (Table 4$)$, more overestimated infants $(22 / 50)$ survived than underestimated $(5 / 50)$ and accurately estimated $(23 / 50)$ infants. However, more infants died in the overestimated group (17/37) than in the underestimated (5/37) and accurately estimated group (15/37).

Taking into account only infants receiving intensive care (Table 5 in initial analysis), $66.7 \%$ survived in the overestimated group (vs. 55.6\%), 83.3\% in the underestimated group (vs. $75.0 \%$ ), and $73.5 \%$ in the accurately estimated group (vs. 79.3\%). There was no significant difference in death between the groups; however, more accurately estimated infants died (20.7\%).

\section{Discussion}

This study is the first to report that inaccuracy of EFW frequently occurs and influences the prediction of neonatal mortality at the limit of viability, potentially influencing neonatal outcome. We demonstrate that EFW is accurate in only $62.1 \%$ during emergency situations in the delivery room. This low number of correct estimations probably reflects the situation in a busy $24 / 7$ delivery suite, where suboptimal conditions for ultrasonography are predominant. These suboptimal conditions may include nonrelaxed patients due to preterm labor and/or emergency situation, nonspecialized operators (no maternal-fetal medicine specialist), and no availability of high-end ultrasound equipment.
If EFW is incorrect, it may affect neonatal outcome, as underestimation might lead to a less active course of action postnatally. However, if full treatment is favored, it may result in better than predicted neonatal outcome. In our cohort, only 1 of 19 (5.3\%) overestimated infants received no postnatal intensive care. In contrast, 6 of 14 $(42.9 \%)$ underestimated infants received no postnatal intensive care. Lung maturation with steroids was complete in less than half of the underestimated infants; however, almost all underestimated infants received lung maturation (Table 1). Thus, overestimated infants receive more intensive care than underestimated ones as overestimated infants may have a higher chance of survival and hence, postnatal intensive care is applied more often. However, overestimated infants have a lower actual birth weight than accurately estimated or underestimated ones (Table 2).

As infants with a gestational age below $24 \%$ weeks (when usually no intensive postnatal care is administered in our center) are underestimated frequently, we subsequently analyzed cases where intensive care was administered. At the 6-week follow-up, more overestimated infants died than accurately estimated infants. At the same time, there is no significant difference in death between accurately estimated and underestimated infants.

Overall, our results for infants receiving postnatal intensive care imply that out of 5 infants who survive, only 1 survives without impairment at the 6-week follow-up. Our overall survival rate of $57.5 \%$ (50/87) for that gestational age range is within the survival range of $36-63 \%$ described in the current literature (including survival to discharge) $[2,3,13-17]$. We only looked at short-term 
survival at 6 weeks postnatally; however, long-term survival has to be considered as well.

The main limitations of our study are the retrospective study design as well as the limited sample size. Thus, we were unable to modify or standardize the criteria for offering intensive care. Furthermore, the impact of confounding factors on EFW might have been underestimated in our study. The strength of our study is that EFW measurement was performed by residents under supervision of a registrar. This is of particular importance as EFW measurements at the limit of viability are frequently performed during emergencies in the delivery room as reflected by our study design. The detected difference in the time interval between ultrasound and birth may also have had an impact on our results. A time interval of more than 7 days between ultrasound and birth leads to inaccurate EFW $[18,19]$. A noncephalic presentation tends to result in underestimation of fetal weight. While the current literature attributes breech presentation to inaccurate EFW, there is no data available for very low birth weight infants $[20,21]$. In contrast, oligohydramnios tends to result in a fetal weight underestimation, as has been shown in the literature [22]. In our cohort, higher maternal body mass index results in an overestimation of fetal weight. The impact of body mass index on EFW is well defined, but with no significant reduction in EFW accuracy $[18,19,23]$. Surprisingly, we did not detect sex differences regarding overall survival $(p=0.375)$. A possible explanation is that only $38 \%$ of all included infants were female as well as the small sample size.

In view of our study showing the frequent inaccuracy of EFW and its impact on estimation of neonatal mortality at a gestational age between $23 \%$ and $26 \%$ weeks, the validity of the neonatal mortality prediction algorithm of the NICHD online tool may be challenged. Adjustment by decreasing the significance of the fetal weight in the algorithm might improve the prediction accuracy. Previ- ous studies have shown that there is greater inaccuracy in EFW for extremely low birth weight infants [24, 25]. However, a recently published study determined EFW to be an important factor in determining neonatal outcome when a difference of $20 \%$ or more was chosen between EFW and birth weight in a study population including mostly African-American women with a higher body mass index than in our group [26]. The inaccuracy of EFW needs to be kept in mind when deciding on a clinical treatment in emergency situations. Overestimated infants might be more likely to receive steroids for lung maturation as well as intensive care while their actual birth weight compared with EFW seems to be the limiting factor concerning neonatal outcome. In addition, obstetrical and maternal complications also have to be taken into account as well as the postnatal care and setting that is available at the respective center.

In our additional analysis with a 15-gram per day weight gain per EFW between ultrasound and birth, the differences between the groups become less significant. However, the distribution of our 3 groups changes, with more infants being overestimated. In addition, the time interval between ultrasound and birth is now greater for the overestimated group, and we cannot assume linear growth of $15 \mathrm{~g} /$ day for all infants. As this is a retrospective study, we cannot presume that clinicians did take a weight gain into account in their decision making; therefore, we might be replacing one measurement bias with another. However, these results support our hypothesis that EFW itself is a confounding factor in clinical decision making at the limit of viability.

\section{Acknowledgments}

We would like to thank Prof. Franziska Tschan, Professor of Social Psychology at Work, University of Neuchâtel, Switzerland, for assistance with statistical analysis.

\section{References}

1 Medlock S, Ravelli AC, Tamminga P, Mol BW, Abu-Hanna A: Prediction of mortality in very premature infants: a systematic review of prediction models. PLoS One 2011;6:e23441.

2 Berger TM, Bernet V, El Alama S, Fauchere JC, Hosli I, Irion O, et al: Perinatal care at the limit of viability between 22 and 26 completed weeks of gestation in Switzerland. 2011 revision of the Swiss recommendations. Swiss Med Wkly 2011;141:w13280.
3 Bajwa NM, Berner M, Worley S, Pfister RE: Population based age stratified morbidities of premature infants in Switzerland. Swiss Med Wkly 2011;141:w13212.

4 Kollee LA, Cuttini M, Delmas D, Papiernik E, den Ouden AL, Agostino R, et al: Obstetric interventions for babies born before 28 weeks of gestation in Europe: results of the MOSAIC study. BJOG 2009;116:1481-1491.
5 Raju TN, Mercer BM, Burchfield DJ, Joseph GF Jr: Periviable birth: executive summary of a joint workshop by the Eunice Kennedy Shriver National Institute of Child Health and Human Development, Society for MaternalFetal Medicine, American Academy of Pediatrics, and American College of Obstetricians and Gynecologists. Am J Obstet Gynecol 2014;210:406-417.
Neonatal Outcome Affected by Fetal Weight Assessment
Fetal Diagn Ther

DOI: $10.1159 / 000450943$ 
6 Pignotti MS, Donzelli G: Perinatal care at the threshold of viability: an international comparison of practical guidelines for the treatment of extremely preterm births. Pediatrics 2008;121:e193-e198.

7 Tyson JE, Parikh NA, Langer J, Green C, Higgins $\mathrm{RD}$ : Intensive care for extreme prematurity - moving beyond gestational age. $\mathrm{N}$ Engl J Med 2008;358:1672-1681.

8 NICHD Neonatal Research Network. Extremely Preterm Birth Outcome Data. http:// www.nichd.nih.gov/about/org/cdbpm/pp/ prog_epbo/epbo_case.cfm (accessed September 1, 2015).

9 Huber C, Zdanowicz JA, Mueller M, Surbek D: Factors influencing the accuracy of fetal weight estimation with a focus on preterm birth at the limit of viability: a systematic literature review. Fetal Diagn Ther 2014;36:1-8.

10 Hadlock FP, Harrist RB, Sharman RS, Deter RL, Park SK: Estimation of fetal weight with the use of head, body, and femur measurements - a prospective study. Am J Obstet Gynecol 1985; 151:333-337.

11 Bancalari E, Abdenour GE, Feller R, Gannon $\mathrm{J}$ : Bronchopulmonary dysplasia: clinical presentation. J Pediatr 1979;95:819-823.

12 Villar J, Giuliani F, Fenton TR, Ohuma EO, Ismail LC, Kennedy SH: INTERGROWTH21st very preterm size at birth reference charts. Lancet 2016;387:844-845.
13 Chan K, Ohlsson A, Synnes A, Lee DS, Chien LY, Lee SK: Survival, morbidity, and resource use of infants of 25 weeks' gestational age or less. Am J Obstet Gynecol 2001;185:220-226.

14 Vohr BR, Wright LL, Dusick AM, Perritt R, Poole WK, Tyson JE, et al: Center differences and outcomes of extremely low birth weight infants. Pediatrics 2004;113:781-789.

15 Field DJ, Dorling JS, Manktelow BN, Draper ES: Survival of extremely premature babies in a geographically defined population: prospective cohort study of 1994-1999 compared with 2000-2005. BMJ 2008;336:1221-1223.

16 Stoll BJ, Hansen NI, Bell EF, Shankaran S, Laptook AR, Walsh MC, et al: Neonatal outcomes of extremely preterm infants from the NICHD Neonatal Research Network. Pediatrics 2010;126:443-456.

17 Berger TM, Steurer MA, Woerner A, MeyerSchiffer P, Adams M: Trends and centre-tocentre variability in survival rates of very preterm infants ( $<32$ weeks) over a 10-year-period in Switzerland. Arch Dis Child Fetal Neonatal Ed 2012;97:F323-F328.

18 Heer IM, Kumper C, Vogtle N, Muller-Egloff S, Dugas M, Strauss A: Analysis of factors influencing the ultrasonic fetal weight estimation. Fetal Diagn Ther 2008;23:204-210.

19 Scott F, Beeby P, Abbott J: Accuracy of estimated fetal weight below 1,000 g. Aust NZ J Obstet Gynaecol 1996;36:129-132.
20 Melamed N, Ben-Haroush A, Meizner I, Mashiach R, Yogev Y, Pardo J: Accuracy of sonographic fetal weight estimation: a matter of presentation. Ultrasound Obstet Gynecol 2011;38:418-424.

21 Chauhan SP, Magann EF, Naef RW 3rd, Martin JN Jr, Morrison JC: Sonographic assessment of birth weight among breech presentations. Ultrasound Obstet Gynecol 1995;6:5457.

22 Edwards A, Goff J, Baker L: Accuracy and modifying factors of the sonographic estimation of fetal weight in a high-risk population. Aust NZ J Obstet Gynaecol 2001;41:187-190.

23 Farrell T, Holmes R, Stone P: The effect of body mass index on three methods of fetal weight estimation. BJOG 2002;109:651-657.

24 Melamed N, Yogev Y, Meizner I, Mashiach R, Bardin R, Ben-Haroush A: Sonographic fetal weight estimation: which model should be used? J Ultrasound Med 2009;28:617-629.

25 Townsend RR, Filly RA, Callen PW, Laros RK: Factors affecting prenatal sonographic estimation of weight in extremely low birthweight infants. J Ultrasound Med 1988;7:183187.

26 Ethridge JK Jr, Louis JM, Mercer BM: Accuracy of fetal weight estimation by ultrasound in periviable deliveries. J Matern Fetal Neonatal Med 2014;27:557-560. 